\title{
A computational approach to the study of the stability of pier riprap at the Middle Fork Feather River
}

\author{
O. Suaznabar, J. Shen, N. Tsou \\ Genex Systems-TFHRC, Mclean, Virginia, USA
}

C. Bojanowski, S. Lottes

Argonne National Laboratory-TRACC, Lemont, Illinois, USA

K. Flora

California Department of Transportation, Sacramento, California, USA

F. Jalinoos, K. Kerenyi

Federal Highway Administration-TFHRC, Mclean, Virginia, USA

ABSTRACT: This paper discusses the use of various technologies and advanced computational modeling techniques that were combined for monitoring the performance of pier riprap on the basis of a field case study - Pier 3 of a bridge over the Middle Fork Feather River - in northern California, USA. The first phase involved capturing the field condition of the bridge site using sonar instrumentation technology in order to obtain high resolution bathymetry data. The second phase entailed enhancement and transformation of the scanned bathymetric data into a 3D CAD model to be used as the initial geometry for numerical modeling. A Fluid Structure Interaction (FSI) numerical approach was applied to simulate the rock incipient motion i.e. shear failure by coupling Computational Fluid Dynamics (CFD) software STAR-CCM+ and a Computational Structural Mechanics (CSM) software LS-DYNA. Several coupled simulations have been performed with varying flow conditions to identify shear failure conditions for the riprap apron.

\section{BACKGROUND AND MOTIVATION}

Local scour at bridge piers is a potential safety hazard of major concern to transportation agencies in the United States. If it is determined that scour at bridge piers can adversely affect the stability of a bridge, scour countermeasures to protect the pier should be considered. Hydraulic Engineering Circular No. 23 (HEC-23), published by the U.S. Federal Highway Administration (Lagasse et al. 2009) provides procedures for designing pier scour countermeasures that have been implemented throughout the United States. Riprap is the most commonly used countermeasure to prevent scour and protect piers from failure. The size of the rock enables them to resist the increased velocities and turbulence caused by the presence of the pier in the flow. The riprap apron extent protects the underlying erodible bed sediment in the periphery of the pier that otherwise might be exposed to the higher bed shear stresses induced by the highly turbulent flow. For better monitoring and assessment of the riprap apron performance placed at a pier it is important to identify the most common modes of riprap failure. A number of researchers (Parola 1993), (Chiew 1995), (Chiew \& Lim 2000), investigated stability and failure of riprap at bridge piers and identified four failure mechanisms; Shear failure - whereby the riprap rocks are entrained by the flow; Winnowing failure - whereby the underlying finer bed material is removed through voids in the riprap layer; Edge fail- ure - whereby instability at the edge of the riprap layer and the bed sediment initiates a scour hole beginning at the perimeter and working inward that ultimately destabilizes the entire layer; Bed-form undermining - whereby under live-bed conditions the riprap layer is destabilized by the fluctuations of the bed level caused by bed forms (e.g., dunes) as they migrate past the pier.

Current policy in the Hydraulic Engineering Circular No. 18 (HEC-18) (Arneson et al. 2012) to estimate scour at bridge piers does not recommend using riprap to protect the pier as part of the design, and it considers riprap placed at bridge piers to be only a temporary countermeasure against pier scour. The reason for this approach is that important data to evaluate the performance of riprap on a continuing basis is missing, and the technical procedures for sizing of riprap for scour countermeasures is based mostly on scaled laboratory tests under ideal controlled conditions. Comprehensive data on monitoring the performance of riprap or other scour countermeasures for pier protection is needed before a change in design philosophy can be considered.

This paper discusses a new advanced methodology that was developed to assess the stability of riprap installed at bridge piers in the field environment, therefore combining interrelated factors such as local riverbed bathymetry, pier orientation in the river, and the non-uniform distribution of flood flow velocities. This approach consists of 1) applying in situ sonar technology to collect high resolution ba- 
thymetry data of the riprap apron installed around the pier and of the riverbed in the area of interest, and 2) from the captured bathymetry data create a $1: 1$ scale $3 \mathrm{D}$ computer model domain to simulate the riprap stability applying a Fluid Structure Interaction (FSI) numerical approach. This approach is based on coupling Computational Fluid Dynamics (CFD) for solving the highly three-dimensional flow induced by the presence of the pier and Computational Structural Mechanics (CSM) for solving the incipient motion of the frictionally connected rocks of the riprap apron i.e. shear failure of the rock. A scour critical bridge over the Middle Fork Feather River in northern California was chosen as a candidate for this project.

\section{CASE STUDY: BRIDGE ON ROUTE 89 OVER THE MIDDLE FORK FEATHER RIVER}

The bridge on State Route 89 over the Middle Fork Feather River is located in northern California, USA. It was built in 1955 and has 3 spans with a total length of $68 \mathrm{~m}$ and a total deck width of $9.8 \mathrm{~m}$. The $\mathrm{CIP} / \mathrm{RC}$ deck on continuous non-composite riveted 3 steel girders sit on two RC abutments and two RC wall piers, all founded on steel H-piles. The bridge has avulsed from a channel realignment project constructed at the time the bridge was built and has readopted its historic streambed and flow path. As a result, the flow now enters the bridge at a strong angle and causes excessive backwater and deep scour at Pier 3 (Figure 1). Between 2009 and 2010 a series of bridge inspection reports showed that the full width and length of the concrete pile cap of Pier 3 was undermined exposing all 12 steel foundation $\mathrm{H}$ piles. The exposed height of the piles was measured as up to $0.99 \mathrm{~m}$ at the Span 2 upstream corner of the pile cap. Furthermore, there was some undermining at the base of the abutment next to Pier 3 .

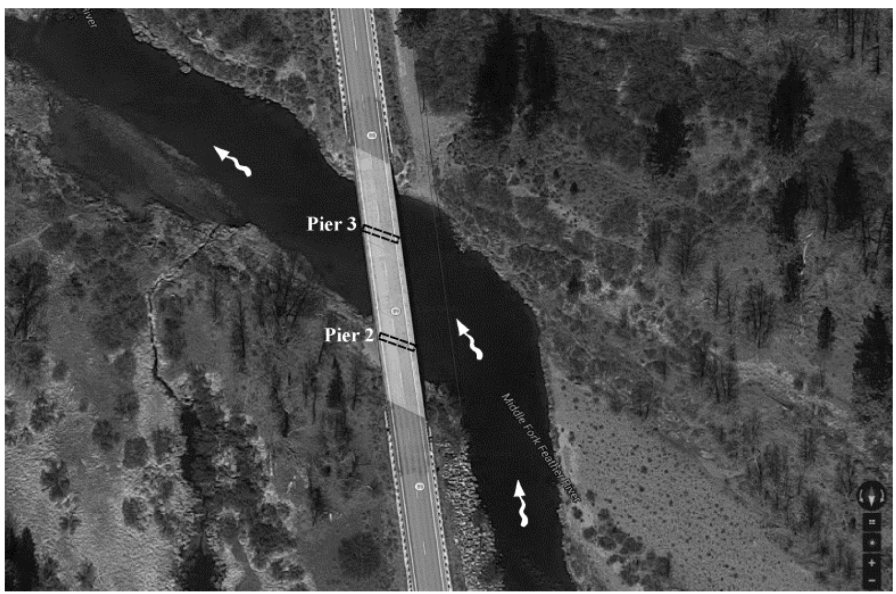

Figure 1 Bridge Site on State Route 89 over the Middle Fork Feather River CA, USA (Source Google Maps 2016).

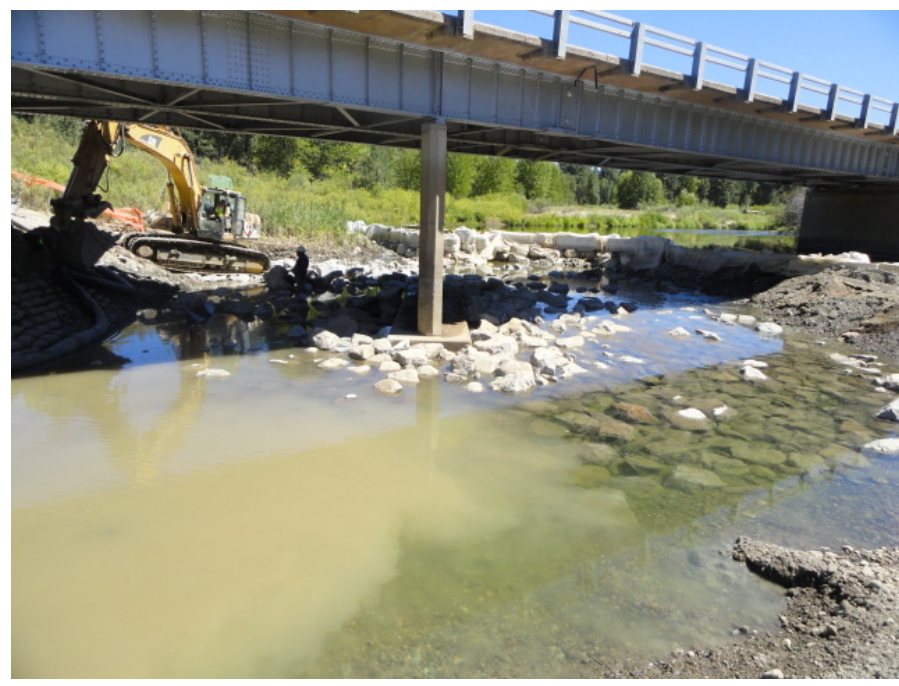

Figure 2 Riprap installation around Bridge Pier 3 at the Middle Fork Feather River

The bridge was determined to be scour critical based on the resulting combination of vertical contraction scour and the local pier scour. To mitigate this scour critical condition, a rock mattress consisting of 1 Ton rock over filter fabric was placed around Pier 3 in 2011 (Figure 2). The channel bed material surrounding the bridge site is largely gravel and cobbles. Based on photos of the bed material along the bank a photo analysis tool was used to assess the gradation, where the particle median diameter of the river bed $D_{50 b e d}=92 \mathrm{~mm}$ with a gradation coefficient in the range of 2.5 to 3 . The rock size and riprap mattress layout placed around Pier 3 were designed according to the guidelines provided by the California Department of Transportation (Caltrans), which are consistent with HEC-23. Based on a 100year design flood the rock median diameter was determined to be $D_{\text {50riprap }}=2.5 \mathrm{ft}(0.76 \mathrm{~m})$ with an equivalent weight of 1 Ton using a specific gravity of 2.67. HEC-23 recommends gradations for several standard classes of riprap based on $D_{50 \text { riprap }}$ that results in riprap that is well graded with an allowable range for the gradation coefficient from 1.5 to 2.5 . However, design of the rock mattress did not consider the increase in flow velocity and shear stress under the structure caused by the flow separation below the superstructure from the vertical contraction of the flow.

\section{SONAR SCAN RESULTS OF THE RIPRAP MATTRESS}

Although underwater acoustic systems were first applied to supplement underwater bridge inspection for many years, newly developed equipment from recent advancements of this technology have resulted in new and improved sonar systems, with which large areas of the river bed can be mapped in an efficient manner. These mapping techniques produce detailed 
images of the area of interest regardless of lighting conditions. Images produced by sonar techniques are now also being used to inspect bridge pier footings and to investigate potential scoured riverbeds around bridge structures.

One of the objectives of this study was finding the most efficient and easily applicable underwater inspection system that could deliver extremely detailed 3D imagery, enable the identification of individual rocks, and collect high-resolution measurement data of the complex surface of the installed riprap mattress at Pier 3. In order to develop approaches for field sonar surveys three different sonar systems were tested to scan the riprap mattress; however, because this project is still ongoing only one of them will be described in this paper, the stationary Multibeam Profiler Sonar that collected the point cloud data that was ultimately post processed to generate the 3D CAD model for numerical simulation. The profiler was deployed on a lightweight tripod with an integrated digitally controlled pan and tilt unit from the bridge deck and also a small boat underneath as shown in Figure 3. The river flowdepth during the survey was in the range of 1.5 to 2 meters around Pier 3. Individual $360^{\circ} 3 \mathrm{D}$ scans (max. range: $100 \mathrm{~m}$ ) with the tripod seating on the river bed and the profiler submerged were taken from different positions around Pier 3 and the riprap mattress.

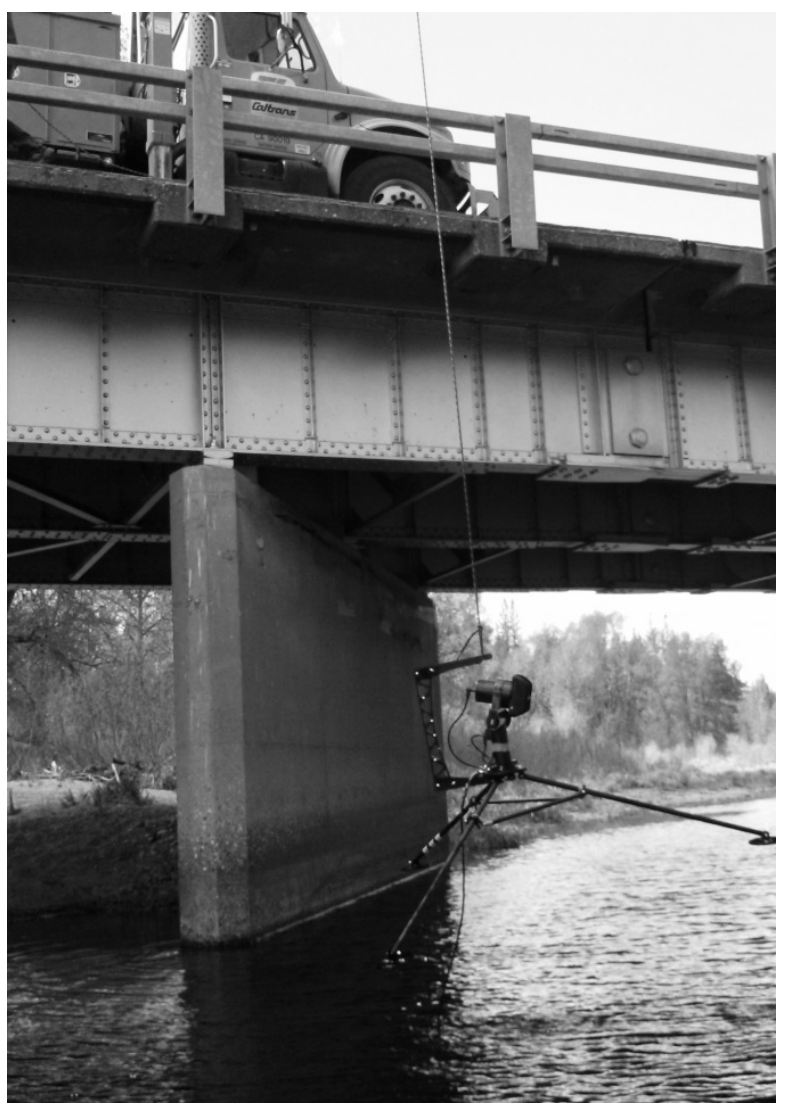

Figure 3 Deployment of the Multibeam Profiler Sonar at the Middle Fork Feather River Bridge.

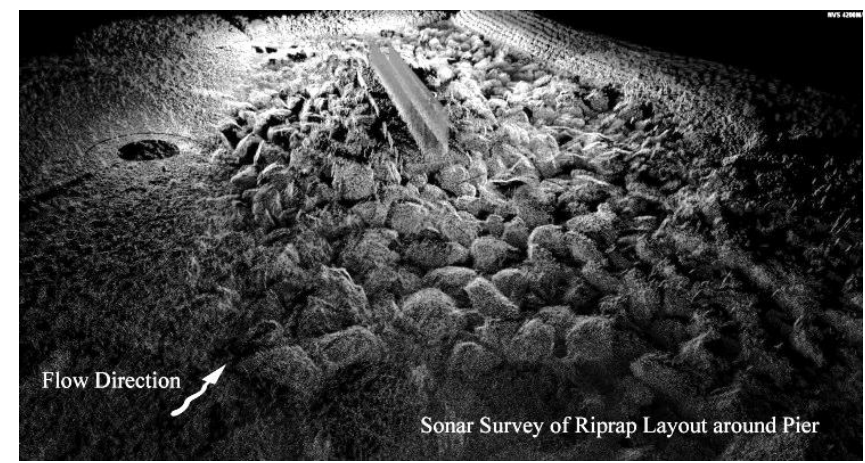

Figure 4 Multibeam sonar scan of the installed riprap apron at Pier 3 of the Middle Fork Feather River Bridge (BlueView Teledyne Marine)

The individual point clouds were merged together into a single, fully rotational 3D image as shown in Figure 4. The sonar inspection revealed the as-built installation layout of the riprap apron around Pier 3. The scanning results were used to create a detailed 3D CAD model of the complex surface envelope of the as-built riprap apron for CFD modeling and to compare the actual as-built condition with the design layout. This comparison was essential to understand how as-built riprap installations may differ from original designs. Figure 5 shows a top view of both riprap layout contours that are overlapped using the same scanned river bed bathymetry as the base line for comparing both conditions, the design layout plan and the as-built riprap mattress obtained from the sonar scans. These are boundary contours of the riprap apron with the actual river bed bathymetry that was scanned together with the as-built riprap mattress at the Pier 3. The advantage of the obtained high-resolution sonar 3D image of the riprap apron was that not only the boundary with the riverbed but also elevations at different points referenced to the pile cap were inspected and compared with the design layout such as whether the riprap apron was installed flush with the pier footing or not, or whether individual rocks were sized accordingly for the design flow conditions.

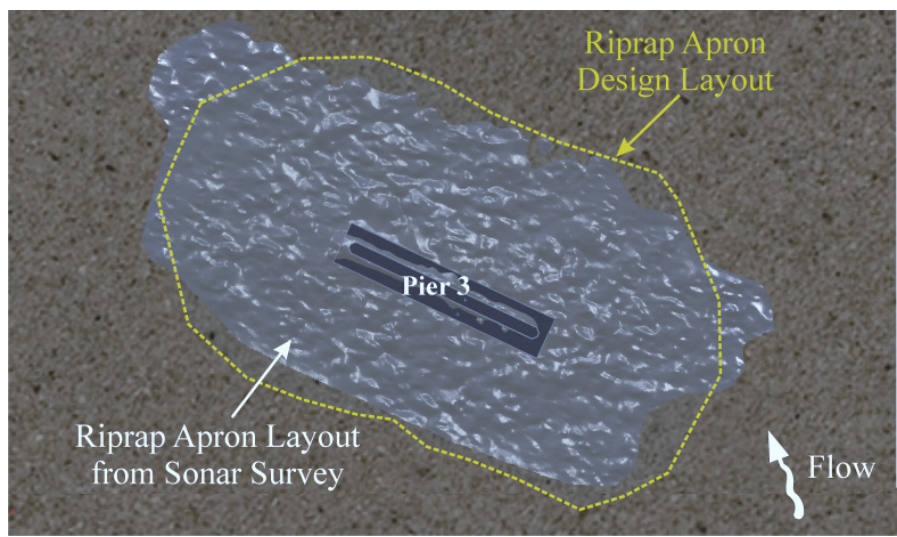

Figure 5. Initial stage of the FSI problem and an intermediate stage with mesh morphing. 
4 NUMERICAL MODELING APPROACH: STABLITY ANALYSIS OF RIPRAP

\subsection{Fluid Structure Interaction (FSI) Concept}

Fluid Structure Interaction (FSI) problems involve solving for the fluid flow force load on a solid surface and the response of the solid to the load. While there has been an interest in solving FSI problems for decades, large computer clusters capable of solving them for full scale systems have only become widely available in the past decade. Recent advances in the capabilities of both computational fluid dynamics (CFD) and computational structural mechanics (CSM) software have made it possible to analyze the onset rock motion of riprap based on highly detailed pressure distribution profiles that act on the surface of rocks. This data is utilized to track the subsequent motion of individual rocks and their interaction with other rocks and/or the solid surfaces of a pier or abutment. The Transportation Research and Analysis Computing Center (TRACC) has licenses for STAR-CCM+ (CFD) and LS-DYNA (CSM) software. FSI approach is based on a coupling process between CFD and CSM software that provides the capability to carry out this type of analysis. In addition, moving and morphing mesh capabilities in CFD software needed to solve FSI problems have only recently matured to the point where they can be reliably used.

Figure 6 presents a schematic of a discretized computational domain with fluid occupying space $\Omega_{f}$ and solid body occupying space $\Omega_{s}$, where $\Gamma_{f}$ and $\Gamma_{s}$ represent known values for different boundary conditions in the domain. Governing laws for the fluid domain $\Omega_{f}$ are the Reynolds averaged Navier-Stokes (RANS) equations for Newtonian incompressible fluids used with a $k-\varepsilon$ turbulence model to solve for the flow field and pressure distribution on the rock surfaces. STAR-CCM+ contains options to select a wide variety of RANS turbulence models. The solid part of the domain $\Omega_{s}$ is governed by conservation equations based upon stress tensors, external surface forces, and contact forces at the interface of two solids in contact. Details on the governing equations for the fluid and structural domains related to this approach can be found in (Bojanowski \& Lottes, 2014). In most classical CFD problems the boundaries are fixed during the analysis, and the computational mesh does not change. In FSI problems the fluid boundaries may be part of a structure that will move or deform in response to surface and body forces that are determined as part of the solution of the problem. As the boundary motion is calculated, the computational mesh in the fluid domain has to be updated either by morphing procedure or a complete domain remesh process. The coupling conditions on the interface between the fluid and solid domains of an FSI problem are:

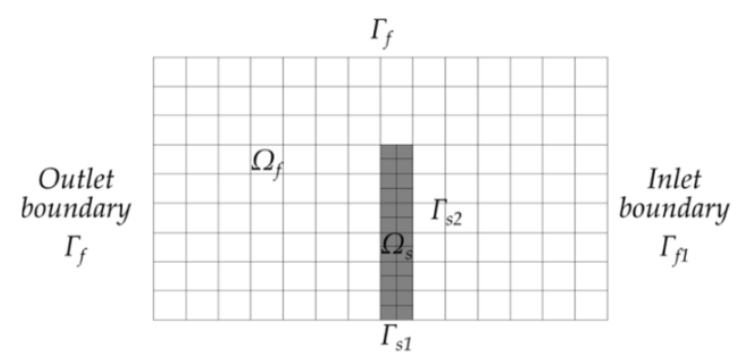

(b)

\section{Mesh morphing}

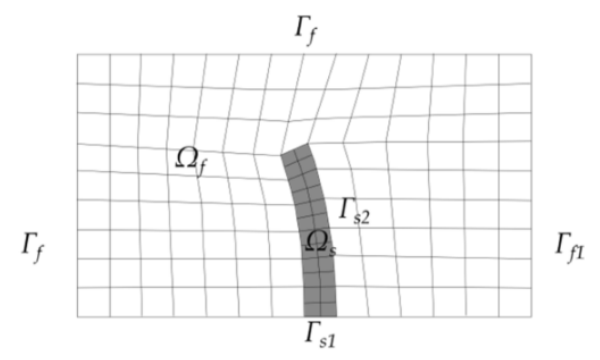

Figure 6. Initial stage of the FSI problem and an intermediate stage with mesh morphing.

$u_{f}=u_{s}$ on $\quad \Gamma_{f}=\Gamma_{s}$
$n \cdot \sigma_{f}=n \cdot \sigma_{s} \quad$ on $\quad \Gamma_{f}=\Gamma_{s}$

where $\sigma_{f}$ and $\sigma_{s}$ are the fluid and solid side stress tensors respectively.

The CFD solution of the fluid flow equations yields the detailed distribution of fluid stress on solid surfaces (left hand side of equation 2). This distribution is passed to the CSM software to solve the response of the solid surfaces (right hand side of equation 1). In general, the surface velocity distribution may include both deformation and rigid body motion. In the analysis of riprap rock motion, it includes only rigid body motion. The motion computed by CSM software is passed to the CFD software as a boundary condition that is a function of time.

\subsection{Coupling Workflow between STAR-CCM+ and $L S-D Y N A$}

The currently implemented coupling involves two separate solvers: STAR-CCM+ performing CFD calculations (CD-Adapco, 2013) and LS-DYNA performing structural analysis (LSTC, 2007 and 2009). Both of these software packages have some FSI capabilities. However, LS-DYNA does not yet have sufficiently robust fluid flow solvers and the wide range of flow physics models available in STAR$\mathrm{CCM}+$, and STAR-CCM+ does not yet have the capability to handle contact forces between the objects that have a meshed geometry. For the purpose of analyzing the onset of motion of riprap rocks, modeling effects of contact forces between objects repre- 
sented in the mesh is an essential feature. For these reasons the analysis is split into two sub problems. STAR-CCM+ calculates the flow field and the pressure distribution on rocks, while LS-DYNA calculates the motion of rocks due to the stresses exerted by the fluid on the rock surface and the effects of contact forces. A new position of a rock after the coupling step is subsequently imported into STAR$\mathrm{CCM}+$ as a basis for the next time step calculation. Because rocks are treated as rigid bodies, a loose coupling procedure that does not account for the acceleration of the rock during the time step is sufficient to obtain first order accuracy in the solution of the rock motion. The small time step required in LSDYNA to handle body interactions and to keep the mesh morphing stable in STAR-CCM+ was assumed to be sufficient to compute the onset of rock motion and the trajectory to adequate engineering accuracy. Figure 6 presents the simplified workflow of the procedure to analyze incipient motion of riprap for a given arrangement and flow velocity. A detailed description of this procedure can be found in (Bojanowski \& Lottes, 2014). The analysis procedure begins with initialization runs that are started manually in both solvers. The LS-DYNA run provides the initial position of the rocks under gravity loading. This position is used as a basis for CFD domain geometry. The CFD model is run until pseudo steady state conditions are achieved with all rocks stationary. Once a CFD time step is converged, the pressure is mapped from the CFD mesh on the rocks to the CSM mesh and exported to file. The resulting displacements vectors from LS-DYNA are extracted so that they can be imported into STAR-CCM+ for the next step. After this the whole loop is repeated until the termination time.

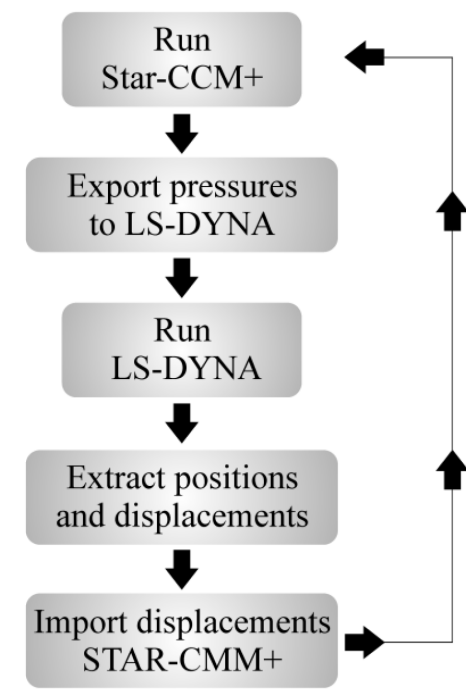

Figure 7. Simplified coupling workflow between STAR-CCM+ and LS-DYNA.

\subsection{Application of FSI Method to the Middle Fork Feather River Pier Riprap Stability Analysis}

A large scale CFD domain was built from the 3D CAD model previously generated from the point cloud bathymetry data of the river bed and of the riprap mattress. The domain was meshed using hexahedral cells with varying cell size, where large areas such as the riverbed and riverbanks upstream and downstream were covered with a coarse mesh while small cell sizes (fine mesh) were used for areas of interest used for coupling procedures. The full scale model domain size of the bridge site at the Middle Fork Feather River was covered with a total of 3.8 million cells (Figure 8). In addition, a single rock model was built by processing the surface point cloud data from a 3D laser scan performed in the TFHRC J. Sterling Jones Hydraulics Research Laboratory of a full scale prototype rock with $\sim 4 \mathrm{~mm}$ spacing between the points. MeshLab software was used to generate a surface triangulation of the rock from the point cloud data. The initial shape and size was subsequently modified by simple geometrical operations to create a set of over 2500 rocks to populate the sonar scanned layout of the riprap mattress at Pier 3. At first all rocks were considered as non-movable in order to run STAR-CCM+ solely for CFD analysis. Subsequently movable rocks were placed randomly in the areas where high forces were expected (Figure 9). A k- $\varepsilon$ turbulence model with Reynolds-Averaged Navier Stokes equations was used to solve the flow field. An implicit unsteady solver with time step of 0.1 seconds was used in the flow solver for 700 seconds. The coupling time step i.e. the rate at which data between the CFD and CSM solvers was exchanged was 0.025 seconds. In LS-DYNA the rocks were modeled as rigid bodies with a specific gravity of 2.67 . The mass of rocks ranged between 0.4 to 1 tons. Three contact definitions were incorporated in the model: (i) among the moving rocks, (ii) between the moving rocks and the stationary rocks and (iii) between the moving rocks and the boundaries. The time step of calculations in the LS-DYNA explicit solver was set to $4.5 \times 10^{-6}$ seconds. Use of the explicit solver and such a small time step was needed to stabilize the contact forces between rocks colliding with other rocks and/or wall boundaries. A time step that is too large can cause excessive contact forces and abnormal behavior of the rocks. Once the STAR-CCM+ and LS_DYNA models were initialized, the coupling between them was automatically activated. 


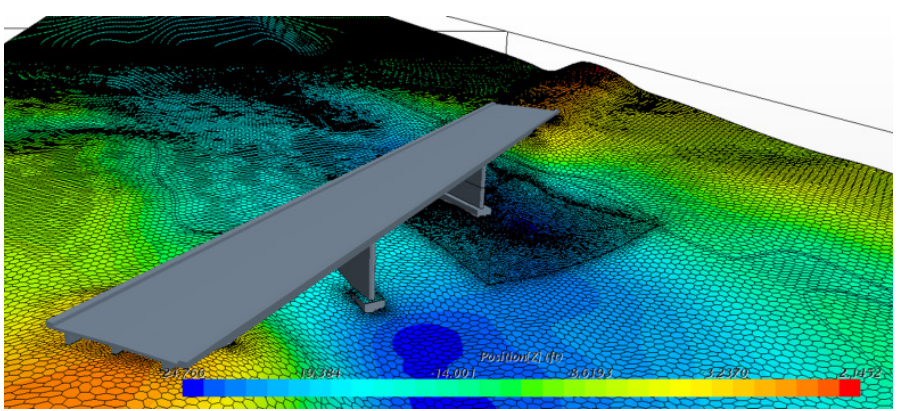

Figure 8. Meshed CFD Model Domain of the Bridge Site at the Middle Fork Feather River

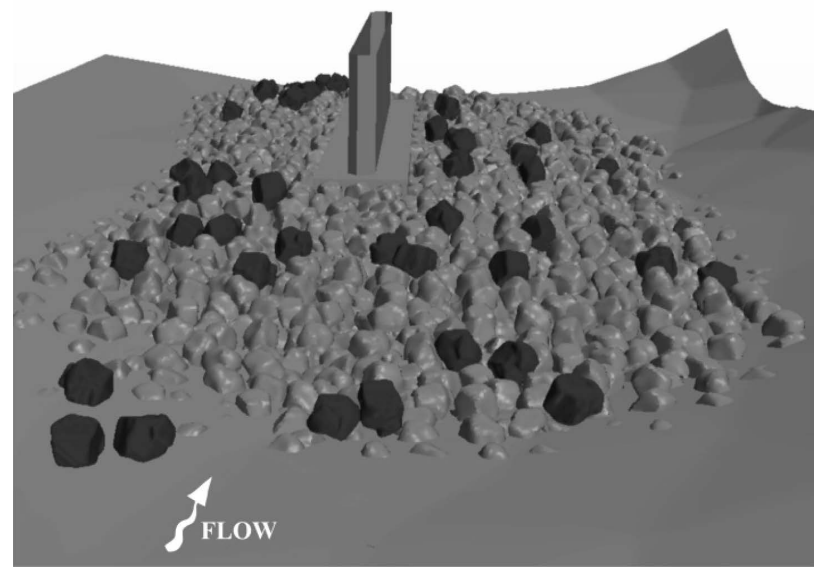

Figure 9. Flow domain showing placement of movable rocks (dark color) within the riprap mattress around Pier 3.

\subsection{Analysis Results}

For the 100-year design flow the discharge used was $\mathrm{Q}=852 \mathrm{~m}^{3} / \mathrm{s}$ with an average flow depth upstream $\mathrm{y}_{\mathrm{U}}=5.8 \mathrm{~m}$ near the bridge opening. From the CFD analysis the depth averaged velocities immediately upstream of Pier 3 were found to be $V_{U}=3.35 \mathrm{~m} / \mathrm{s}$. Peak velocities of $4.7 \mathrm{~m} / \mathrm{s}$ were observed right downstream of Pier 3. Furthermore a 2D flow analysis was performed for the same 100-year flow conditions using TUFLOW in order to compare simulation differences between 2D and 3D flow analysis. While the 2D analysis predicted overtopping of bridge deck, CFD analysis with STARCCM+ did not. The first coupled simulations used 0.4 ton sizing for the movable rocks to verify the onset of motion computation. Subsequently up to one hundred 1 Ton movable rocks, sized according to HEC-23 design guidelines, were placed in the areas where high forces were observed from the results of the previous STAR-CCM+ CFD analysis that was modeled using a fixed-rock riprap mattress around Pier 3. From the coupling results between STAR-CCM + and LSDYNA for the model using movable 1 Ton rocks and a 100-year design flow condition local entrainment of several rocks were detected both adjacent and away from Pier 3. Especially the rocks that were positioned not accurately flush within the riprap mattress were entrained by the flow, regardless of in reference to Pier 3 . Figure 10 shows shear failure re- sults from LS-DYNA in a sequence of snapshots for three movable 1 Ton rocks 1,2 and 3 placed around Pier 3, where for the first snapshot in the sequence time 0 seconds represents the instant when the incipient failure starts for rocks 1 and 3 . The second snapshot at time 0.8 seconds shows rock 1 colliding with rock 2 which consequently starts moving downstream of Pier 3 . The third snapshot at time 1.55 seconds shows rocks 1,2 and 3 moving/rotating in downstream direction and away of the riprap mattress.
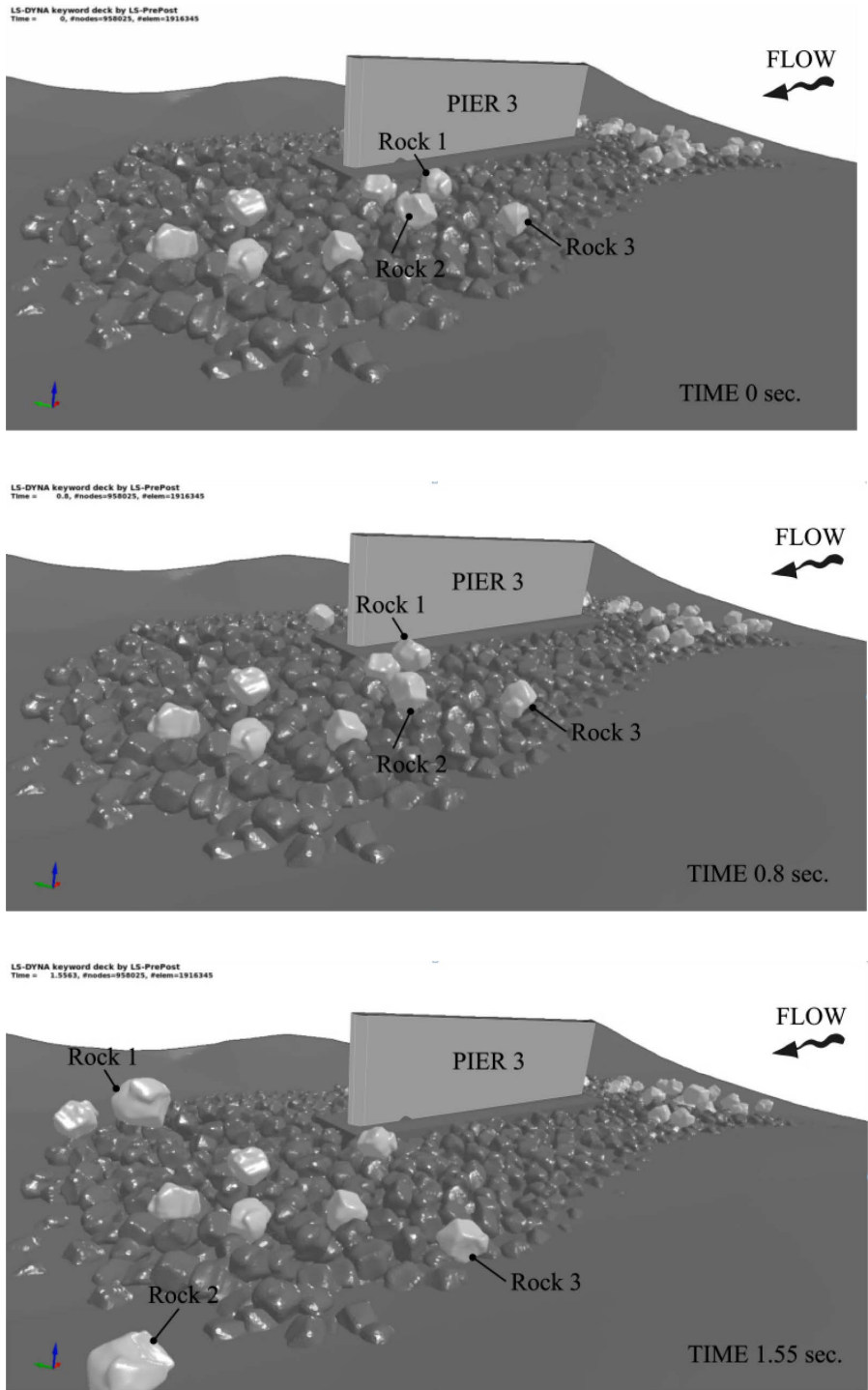

Figure 10. Snapshots showing the shear failure of 1-Ton rocks 1, 2 and 3 placed around Pier 3 induced by flow forces.

\section{SUMMARY AND CONCLUSIONS}

A computational approach was developed by coupling STAR-CCM+ software and LS-DYNA software to solve fluid structure interaction problems (FSI). This procedure includes automated mapping and data exchange of the interface coupling conditions between the two software solvers. A field case study - Pier 3 of a bridge over the Middle Fork Feather River - in northern California, USA was 
chosen to study this advanced methodology developed to assess the stability of riprap installed at bridge piers in the field environment during a flood event. This project study utilized the application of multibeam sonar scan of the installed riprap apron at Pier 3 of the Middle Fork Feather River Bridge in order to enable the identification of individual rocks. Based on the high-resolution scanned data obtained a detailed 3D CAD model of the complex surface envelope of the as-built riprap apron was built for the FSI numerical model approach and the scanned data was also used to compare the as-built condition with the design layout. The numerical coupling method was successful in detecting the incipient motion of large rocks in the riprap installation around Pier 3 induced by flow forces. This combined technique can be utilized to determine riprap sizes for major bridge projects and/or to assess riprap installations considering many interrelated factors such as local riverbed bathymetry, pier orientation in the river, and the distribution of flood flow velocities.

\section{ACKNOWLEDGEMENTS}

The authors would like to thank the Argonne National Laboratory, for the use of the high performance computers at Argonne's Transportation Research And Analysis Computing Center (TRACC).

\section{REFERENCES}

Arneson, L.A., Zevenbergen, L.W., Lagasse, P.F. \& Clopper, P.E. 2012. Evaluating Scour at Bridges. Hydraulic Engineering Circular No.18. Washington D.C.: FHWA

Bojanowski C. \& Lottes S. 2014. Development of a Computational Approach to Detect Instability and Incipient Motion of Large Riprap Rocks. Proc. Transportation Research Board Annual Meeting, Washington D.C.: TRB

CD-Adapco 2013. User Guide STAR-CCM+ Version 8.02.

Chiew, Y.M. 1995. Mechanics of Riprap Failure at Bridge Piers. Journal of Hydraulic Engineering. 121(9): 635-643.

Chiew, Y. \& Lim, F. 2000. Failure Behavior of Riprap Layer at Bridge Piers under Live-Bed Conditions. Journal of $\mathrm{Hy}$ draulic Engineering. 126(1): 43-55.

Lagasse, P.F., Clopper, P.E., Pagán-Ortiz, J.E., Zevenbergen, L.W., Arneson, L.A., Schall, J.D. \& Girard, L.G. 2009. Bridge Scour and Stream Instability Countermeasures. Hydraulic Engineering Circular No. 23. Washington D.C.: FHWA

Livermore Software Technology Corporation (LSTC) 2007. LS-DYNA ${ }^{\circledR}$ User's Manual Version 971.

MeshLab 2013. http://meshlab.sourceforge.net/

Parola, A.C. 1993. Stability of Riprap at Bridge Piers. Journal of Hydraulic Engineering. 119(10): 1080-1093.

Teledyne BlueView Inc. 2014. www.blueview.com/ 